\title{
Criação do jogo para corais infantis
}

\author{
Rafael Keidi Kashima \\ Universidade Estadual de Campinas \\ rafaelkeidi@gmail.com
}

\begin{abstract}
Resumo: Este artigo, oriundo de uma dissertação de mestrado, buscou propor uma sequência de etapas para o desenvolvimento do jogo didático nos ensaios de coros infantis para além do seu caráter recreativo, e sim como uma ferramenta interessante para o aprendizado do repertório musical. Recorrendo aos estudos bibliográficos da literatura vigente relacionada aos jogos, regência coral e educação musical, considerou-se a organização destes conceitos para que a presença do jogo nos ensaios seja justificada e possa promover juntamente significado no aprendizado e avanço na qualidade da performance. Considerou-se que o regente é responsável pelos ensaios e cabe a ele, planejar propostas dinâmicas evitando o abuso do ensino mecanizado que muitas vezes tende a distanciar o interesse da criança do ensaio.
\end{abstract}

Palavras-chave: Coral infantil. Jogos. Educação Musical.

\section{Creation of the game for children's choirs}

Abstract: This paper was formulated from a master's thesis sought to propose a sequence of steps for the development of the didactic game in the rehearsals of children's choirs, in addition to its recreational character, but as an interesting tool for learning the music repertoire. Through bibliographic studies of the current literature related to playing games, choral conducting and music education, it was considered the organization of these concepts so the presence of the game during the rehearsals is justified and can promote meaning in learning and progress in the quality of the performance. It was considered that the conductor is responsible for applying tests and it is up to him to plan dynamic proposals avoiding the frequency of mechanized teaching which often tends to distance the child's interest from the choir rehearsal.

Keywords: Children Choir. Games. Music Education.

\section{Introdução}

Este artigo propõe uma sequência de etapas que auxiliam ao regente na criação de jogos para corais infantis como alternativa para o ensino da performance. A inspiração desta pesquisa se deu a partir das análises contidas na dissertação de mestrado "A função e o desenvolvimento do jogo didático nos ensaios de coros infantis" (KASHIMA, 2014) onde é discutido o jogo como ferramenta pedagógica. Nessa dissertação foram realizadas entrevistas com regentes de coros infantis escolares de Campinas, a respeito do funcionamento do jogo dentro dos seus respectivos ensaios. $\mathrm{Na}$ análise das entrevistas, o autor aponta que o jogo é melhor compreendido e utilizado nos ensaios por ser divertido. Constatou-se que as/os regentes entrevistadas/os incorporavam este tipo de atividade porque era reconhecido que as crianças gostavam 
de jogar, porém, não associavam os aprendizados proporcionados pelo jogo com os desafios do repertório musical:

Constata-se uma divisão entre jogar e ensaio construída e aplicada pelos regentes B, C, D e F. Eles compreendem a necessidade do jogo no ensaio por razões motivacionais e acreditam que as habilidades adquiridas pelo jogo podem auxiliar nas vivências musicais dos alunos, porém, para eles, o jogo não está incorporado na "raiz" da rotina, ele é paralelo às atividades que o regente escolheria utilizar inicialmente para desenvolver alguma habilidade, o que possivelmente se intensifica no processo de passagem do repertório novo (KASHIMA, 2014, p. 58).

Rompendo com o uso do jogo unicamente de forma recreativa, discute-se aqui a possibilidade de concebê-lo também como ferramenta de ensino do repertório musical, ampliando a suas funcionalidades e relevâncias dentro da prática coral. Como proposta, este estudo aconselha uma sequência de etapas que facilitam a criação de jogos que contribuem para o aprendizado da performance.

Neste artigo o jogar e o brincar serão tratados como atividades que possuem a mesma função na vida humana, sendo assim, as características que os definem como tais transitam no universo das duas palavras, tornando-as conceitualmente como sinônimas. Além de que nos idiomas de alguns dos principais autores estudados, como no caso do holandês: spelen (língua original do autor Huizinga (1995)) e no francês: jouer (língua original do autor Brougère (1995)), estas palavras podem ser traduzidas como jogar ou brincar.

Baseado nos estudos de Staalduinen e Freitas (2011) sobre o desenvolvimento de jogos digitais pedagógicos, aqui são apresentadas quatro etapas bases para a elaboração de jogos didáticos para o ensino coral. Estes autores defendem que para criá-los, o processo se inicia pelo estudo de como eles funcionam no âmbito da aprendizagem e pela identificação de quais serão os saberes esperados pela sua prática. Parte-se em seguida para a estruturação das suas regras e a avaliação da sua efetividade, junto aos jogadores e jogadoras (STAALDUINEN; FREITAS, 2011, p. 44). Buscando se aproximar desta lógica, sugere-se que na prática coral, a criação dos jogos perpassa pela conscientização de sua importância na perspectiva do ensino da performance, seguida pela escolha do que será ensinado. Obtendo os objetivos de ensino, parte-se para a criação do universo do jogo em si e o planejamento de quando ele ocorrerá nos ensaios para ser avaliado junto às crianças. 


\section{O jogo, a criança e o ensaio coral}

Segundo Brougère (1995), as crianças são inseridas na cultura das brincadeiras pelos adultos com quem elas convivem. Pela ludicidade característica do jogo, a criança reproduz muito do seu cotidiano, reelaborando-o pela sua imaginação. Elas agem motivadas pelas referências que possuem, mas constantemente se adaptam a partir das novas relações sociais e pela possibilidade de diferentes interpretações de objetos e ações.

$\mathrm{Na}$ medida em que se desenvolvem, mediadas pela sua cultura, as crianças definem que estão brincando e essa habilidade supõe distinguir o brincar de outras atividades cotidianas, a partir da imagem que produzem da própria ação. Sendo assim, um jogo no ensaio coral só será de fato interpretado como tal, caso as crianças cantoras acreditem que estão jogando.

Para Vigotski (2000), as crianças começam a criar situações imaginárias brincando, e a sua prática estimula a variação da atribuição do sentido das coisas e dos contextos. As crianças vão se libertando das amarras da realidade imediata tendo a oportunidade de controlar e atuar em novas situações lúdicas. Mesmo que a criança esteja somente sentada em uma cadeira, todo o tempo, o espaço e a atividade ganha um novo sentido e propósito já que ela pode brincar que está pilotando um avião através da imaginação. $\mathrm{O}$ autor também observa que pelo jogo, a criança ocasionalmente demonstra comportamentos aquém do esperado para sua idade. Brincando, ela cria a Zona de Desenvolvimento Proximal: "define aquelas funções que ainda não amadureceram, mas que estão em processo de maturação, funções que amadurecerão, mas que estão presentemente em estado embrionário" (VIGOTSKI, 2000, p. 113) sendo a definição do espaço entre a Zona de Desenvolvimento Real, que são as atividades que as crianças podem realizar sozinhas e a Zona de Desenvolvimento Potencial, no qual, as crianças conseguem realizar a atividade com alguma ajuda. Esta potencialização de habilidades proporcionada pela ação no jogo impulsiona o aprendizado de saberes que estavam latentes, acompanhado de criatividade, prazer e motivação.

Importante destacar o prazer existente no exercício do jogo. Nas diferentes etapas do desenvolvimento da criança, a função e o prazer associado ao jogo se altera 
gradativamente vinculado com as suas experiências sociais. Cória-Sabini e Lucena (2004) discutem que quando a criança joga, ela apresenta sinais de prazer e esta sensação se mantém até que o jogo acabe. A procura desta sensação é um dos seus principais motivadores, embora a contribuição da atividade do jogo vá bem mais além desta qualidade.

Usar o jogo na educação significa transferir condições para que no campo no ensino-aprendizagem, as crianças construam o conhecimento introduzindo propriedades de diversão, prazer e estímulo da criatividade, além de que as vivências lúdicas “contribuem poderosamente no desenvolvimento global" (NEGRINE, 1994, p. 19). No canto coral, devido à necessidade de repetição para o aprendizado do repertório, a prática do jogo é uma alternativa interessante para que a criança aprenda a música criando vínculos positivos com os ensaios. Busca-se, evitar a tentativa de suprir um problema na performance somente repetindo a mesma canção sem fazer o uso de estímulos diferenciados que seriam possíveis no contexto do jogo.

Figueiredo (1990) defende a importância de dinâmicas variadas nos ensaios, já que essas diversificações de atividades propiciam a ampliação das possibilidades de assimilação de conceitos. $\mathrm{O}$ autor pondera que "[...] a variedade nas atividades pode conduzir a compreensão de maneira a evitar os condicionamentos que transformam o treinamento num fim em si mesmo" (FIGUEIREDO, 1990, p. 30), pois tais condicionamentos descartam os interesses das crianças dificultando a elaboração de sentido naquilo que exercem. Nesta mesma perspectiva, para Coll (2000), proporcionar atividades prazerosas e consequentemente significativas é fundamental nos processos de ensino, favorecendo o aprendizado dos conteúdos específicos, assim como aqueles necessários para a performance coral:

O que importa é que os alunos possam construir significados e atribuir
sentido àquilo que aprendem. Somente na medida em que se produz este
processo de construção de significados e de atribuição de sentido se
consegue que a aprendizagem de conteúdos específicos cumpra a função
que lhe é determinada e que justifica sua importância: contribuir para o
crescimento pessoal dos alunos, favorecendo e promovendo o seu
desenvolvimento e socialização (COLL, 2000, p. 14).

Nos ensaios em que existam os jogos também são criados mais espaços para a movimentação corporal. Dentro do jogo, a criança tem espaço para poder se 
movimentar livremente e explorar as potencialidades do seu corpo, motivadas pela ludicidade e o prazer. Em seus estudos, a autora Strolli (2011) defende que o corpo não é meramente um instrumento a ser adestrado, nem um "recipiente" vazio a ser preenchido com habilidades, mas sim o principal agente de transformação individual e ao seu redor, através de suas ações:

\begin{abstract}
Pode-se dizer que é através de sua ação que o corpo realiza processos de aprendizagem e dessa forma incorpora o conhecimento, ou seja, esta passa a fazer parte do corpo. Considerando essa questão no âmbito do processo de cognição musical, entende-se que o ambiente para que esse processo ocorra deve ser instaurado pela própria ação do corpo. E a ação do corpo no mundo ocorre primordialmente através do movimento (STROLLI, 2011, p. 136).
\end{abstract}

Os benefícios do movimento corporal vinculado com o aprendizado musical são difundidos desde a disseminação dos ideais dos métodos ativos da educação musical. Estes métodos são os processos pedagógicos que almejam possibilitar a experiência direta da aluna e aluno, a partir do contato e vivência dos elementos musicais. No início do século XX, "como resposta a uma série de desafios provocados pelas mudanças na sociedade ocidental" (FONTERRADA, 2003, p. 107), estes ideais foram disseminados e aprofundados por diversos educadores musicais, visando a preocupação "específica em cuidar do desenvolvimento e do bem-estar da criança, ou mesmo do jovem e do adulto" (FONTERRADA, 2003, p. 109). Ao invés de atividades que usam exclusivamente a imitação da movimentação já construída, um jogo dramático também favorece que a criança atue mais ativamente no processo de criação artística.

Salienta-se que diversos benefícios são proporcionados por meio do jogo dramático, dentre eles: o estímulo da criatividade, a iniciativa, fortalecimento da concentração, desenvolvimento da coletividade (habilidade de extrema importância para o trabalho coral), ampliação do repertório de movimento e exploração corporal, memorização da letra das canções, além de favorecer a desinibição para a performance (SPOLIN, 2006, p. 20). Através da dramatização, Koudela (2007) também observa que o entendimento da linguagem, do texto e da expressividade musical é facilitada quando as/os cantoras/es conseguem se colocar no eu-lírico das canções através dos jogos.

O ajustamento da realidade a suposições pessoais é superado a partir do momento em que o jogador abandona a sua história de vida (psicodrama) e interioriza a função do foco, deixando de fazer imposições artificiais a 
si mesmo e permitindo que as ações surjam da relação com o parceiro (KOUDELA, 2007, p. 23).

Sinteticamente, os jogos propiciam o prazer no aprendizado, estimulam a ludicidade e na maioria das vezes promovem a movimentação corporal, elementos estes que só acrescentam e favorecem o aprendizado e o desenvolvimento global. Estas características evidenciam que as crianças gostam de brincar e que nos ensaios estes momentos contribuem para o seu bem-estar.

Ciente da sua relevância, a próxima etapa é a projeção da performance artística do coral para que a/o regente possa decodificar quais serão os objetivos de ensino almejados, visando incluí-los no universo dos jogos.

\section{Projeção da performance}

Clarke (1999) descreve que a performance é a execução física e musical que expressa uma ideia narrativa, exigindo assim, um conjunto de ações que transpassam o cantar corretamente. Com as suas vozes e corpos, as crianças expressarão intenções subjetivas artísticas e para isso, utilizarão as referências e aprendizados que foram desenvolvidos nos ensaios. Vale ressaltar que a/o regente é o guia musical e performático das crianças, assim, seu conhecimento perpassa pelo domínio desta linguagem e da prática do ensino de canto coletivo.

Ao criar um jogo, a/o regente primeiramente escolhe o principal objetivo de ensino que auxiliará na execução de algum desafio existente no repertório. Supõe-se que a/o regente escolheu a canção "Alô, alô galera”, da compositora Thelma Chan ${ }^{1}$. Na execução vocal desta música, a criança precisa mudar da voz falada para a voz cantada rapidamente, pois possui um rap. Neste caso, considera-se que o objetivo de ensino será a aquisição da habilidade da mudança do timbre vocal. Como exemplo, observe o seguinte jogo:

\footnotetext{
${ }^{1}$ A partitura se encontra no link: http://repositorio.unicamp.br/bitstream/REPOSIP/284386/1/Oliveira_CleodicelesBrancoNogueirade_M.p df. Acesso em: 15/05/2020 (OLIVEIRA, 2012, p. 61).
} 


\section{Jogo dos timbres:}

Objetivos: estimular a variedade e/ou uniformidade do timbre vocal; repetir o repertório já assimilado; técnica e afinação vocal.

Material necessário: placas de papel com desenho com personagens lúdicas ou animais reconhecidos e/ou criados pelas crianças.

Tempo estimado: o tempo está relacionado à duração da canção escolhida para a atividade.

Procedimentos: Combine com as crianças a representação e execução vocal de cada placa, isto é, sugira ou desenvolva coletivamente qual será o timbre vocal correspondente que será executado durante a apresentação de uma placa. Durante a execução da canção, as placas vão se alterando. As crianças, em resposta ao estímulo visual, gradativamente mudam o timbre. Busque também observar possíveis exageros insalubres à saúde vocal e alertá-las dos seus danos, realizando eventuais correções. Nesta mesma atividade, outras figuras podem ser utilizadas para estimular variados timbres, dinamizando a alternância das placas:

a) Voz cantada: uma placa com um pássaro, sugerindo que as crianças cantem afinadas.

b) Voz falada: uma placa com um desenho de várias crianças falando e brincando, sugerindo que as crianças falem.

Pela ludicidade e variedade de ações estimuladas neste jogo, as crianças podem explorar mais livremente os timbres de suas vozes e repetirem a canção selecionada, impulsionadas pelo prazer e ludicidade que existe na ação dentro deste jogo.

A performance do coro também perpassa pela postura e posicionamento espacial de cada criança. Mesmo nos grupos que não executam grandes coreografias, ainda é necessário ensinar onde cada criança se posicionará nos ensaios e nos concertos. Neste cenário, um objetivo de ensino possível pelo jogo seria a memorização espacial das crianças na performance. O jogo "Pula, pula, pipoquinha" visa estimular a execução vocal e percepção sonora do intervalo melódico de terça menor e a memorização da espacialidade. A sua estrutura possibilita que simultaneamente as crianças cantem, se organizem no espaço e brinquem em grupo. 
2. Jogo: "Pula, pula, pipoquinha":

Objetivos: estimular a espacialidade; memória; assimilação do intervalo de terça menor; afinação vocal.

Tempo estimado: 5 minutos.

Procedimentos: após aprender a canção, as crianças se locomovem cantando e pulando como pipocas partindo de uma posição específica no espaço. No momento em que é cantado "Cada um no seu lugar", todos voltam à sua posição inicial, marcado pela pulsação rítmica.

Exemplo 1 - Kashima; Almeida, "Pula, pula, pipoquinha", c. 1-8.

\section{Pula, Pula, Pipoquinha}

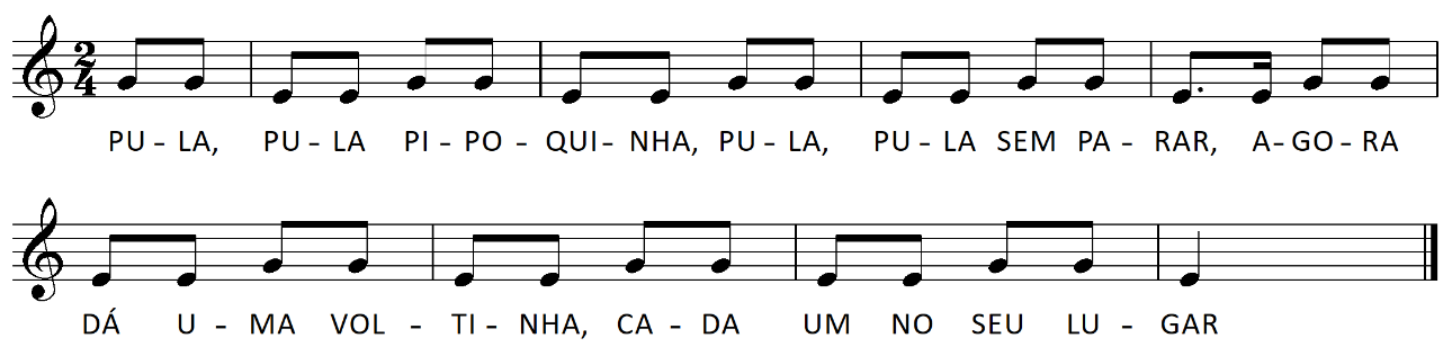

Fonte: KASHIMA, 2014.

Sinteticamente, propõe-se que a/o regente selecione um ou mais conteúdos vinculados à canção do repertório para que seu jogo corresponda com esses objetivos. $\mathrm{O}$ repertório musical já precisa estar escolhido pois, sem esta antecipação seria impossível criar um jogo que corresponda diretamente com o que se pretende performar.

Sabendo o objetivo de ensino, inicia-se a etapa de criação ou adaptação do universo do jogo e para isso, faz-se necessária a ciência de quais são as caraterísticas que o diferem de outras atividades cotidianas. Respeitando estas particularidades, o jogo 
criado tem mais potencial para funcionar na perspectiva de favorecer o aprendizado esperado pela sua prática.

\section{O jogo}

Huizinga (1995) descreve o jogo como presente em todas as culturas e com distintas formas de manifestações. Seria uma ação inata dos seres humanos, porém, não é possível defini-lo com exatidão; portanto, segundo o autor, devemos nos deter em analisar as suas principais características, pois o seu conjunto ajuda a definir uma atividade como jogo:

- Tempo e espaço obrigatoriamente delimitados;

- $\quad$ Existência de regras que são acompanhadas de tensão e/ou alegria;

- $\quad$ Apresenta-se como uma atividade voluntária;

- $\quad$ Distanciamento subjetivo da vida cotidiana (HUIZINGA, 1995, p. 33).

Para Huizinga (1995, p. 27), o tempo e o espaço são fundamentais para a existência do jogo e quando não são reconhecidos, não é possível praticá-lo. O espaço não é necessariamente o físico, como uma quadra esportiva, é também o deslocamento do espaço real para aquele proposto subjetivamente pelo cenário do jogo. Para uma criança jogadora, a cozinha de qualquer casa, em algum determinado momento pode se tornar uma nave espacial em uma aventura futurística. Na brincadeira de "faz de conta", tudo o que a criança vê pode ser diferente do real por meio de sua imaginação, porém, assim que a brincadeira termina, o espaço se torna novamente aquilo que ele objetivamente representa. Este deslocamento espacial imaginário, subjetivo, tem um começo e um fim, delimitando o tempo de sua existência.

Outra característica tratada pelo autor $(1995$, p. 28) é que todo jogo tem suas regras e são elas que determinam aquilo que "vale" dentro do universo temporário por ele circunscrito. Quando não são seguidas, não se está jogando conforme o esperado, criando, assim, uma desordem. Evidentemente, brincando sozinhas ou em grupo, as crianças podem ir mudando as regras ao longo da própria ação, mas sempre delimitando o que farão ou não para se manterem jogando. 
Huizinga (1995) também considera que caso uma pessoa não tenha nenhum interesse inicial no jogo (participação obrigatória), a princípio ela não está efetivamente jogando. Porém, durante a sua prática é possível que ocorra o que o autor denomina como arrebatamento, pois “[...] todo jogo, é capaz a qualquer momento, de absorver inteiramente o jogador" (HUIZINGA, 1995, p. 11). Sinteticamente, defende-se a ideia de que, no momento em que o/a jogador/a descartar a obrigatoriedade, insere-se no universo proposto pelo próprio jogo, tornando-se jogadores/as ativos/as. Quando arrebatadas, as crianças perdem a sensação da obrigatoriedade do jogo que pode causar certo desconforto, e se inserem espontaneamente neste universo.

Freire (2002) compreende que no jogo existe a predominância da subjetividade. As/os jogadoras/es estão conectadas ao universo do jogo mais do que ao mundo real ocorrendo uma expansão de possibilidades de ação que muitas vezes só são possíveis quando se está jogando, entretanto, mesmo com esta predominância, ainda existe o real. Essa dinâmica do real com o não real é exemplificada com a brincadeira de "cavalinho", já que potencialmente a escolha de qual objeto será o "cavalinho" não é totalmente aleatória: "escolher um bastão é mais comum do que a escolha de uma mesa, já que o movimento para subir no bastão aproxima-se mais do cavalinho real do que ao subir em uma mesa" (FREIRE, 2002, p. 2).

O conflito entre o que é subjetivo e o que é objetivo no jogo também é possível de ser percebido nas atividades pedagógicas. Brougére (1995) explica que isto ocorre porque o/a educador/a comumente escolhe o jogo para atrair o interesse das crianças nas atividades e durante sua prática objetiva determinados aprendizados, "porém, a criança não toma a iniciativa da brincadeira, nem tem o domínio de seu conteúdo e de seu desenvolvimento" (BROUGÈRE, 1995, p. 96), interessada somente pela ação, participa motivada sem necessariamente ter preocupações com o seu aprendizado.

Destaca-se que a avaliação das características fundamentais propostas por Huizinga (1995) do que seria ou não jogo também perpassam pela cultura do observador. Segundo Kishimoto (2006) as qualidades do que é jogo podem variar de acordo com a cultura, já que algumas atividades podem ser definidas como jogo e nãojogo ao mesmo tempo, dependendo do significado atribuído. A autora utiliza o exemplo dos indígenas brasileiros para definir atividades consideradas como jogo e não-jogo: 
uma pessoa de fora desta cultura, ao ver crianças usando arco e flecha para caçar animais pequenos, pode imaginá-las como participantes de uma brincadeira, entretanto, para os indígenas adultos, existe a percepção de que a criança está se preparando para suas futuras habilidades de caça necessárias à sobrevivência. Corroborando com esta ideia, Brougère nos diz que "para que uma atividade seja um jogo, é necessário então que seja tomada e interpretada como tal pelos atores sociais em função da imagem que têm dessa atividade" (BROUGÈRE, 1995, p. 22). Desta forma, no canto coral só será possível avaliar se o jogo criado é compreendido como tal quando ele estiver acontecendo com as crianças e elas estiverem arrebatadas por seu universo.

Visto as características que definem os jogos e retomando as etapas de sua criação, imagine que a/o regente queira ensinar a canção "Uirapuru" do Waldemar Henrique $^{2}$. O objetivo de ensino eleito para o jogo é a memorização do poema, pois ele trata de uma narrativa com três estrofes com a mesma melodia, podendo ocorrer certa dificuldade e confusão. Espera-se que envolvidas ludicamente com o jogo, as crianças obtenham mais ferramentas para memorizar e compreender a letra sem a necessidade da repetição exaustiva vocal.

Na criação do jogo, dado o objetivo de ensino (compreensão e memorização da letra), selecionam-se as ações que dentro do jogo favorecerão o aprendizado (ler, desenhar, resumir a sequência, dramatizar, entre outras). Estas ações devem ser inseridas em um universo lúdico (jogo de faz-de-conta, adivinhação, mímica, etc.) com o tempo, as regras (estrutura do jogo) e os espaços bem delimitados. Faz-se necessário também que haja a ciência de que este universo é de interesse da criança, isto é, considera-se o que elas provavelmente gostariam de jogar. Observe a seguinte possibilidade de jogo dramático:

3. Jogo "Teatro mímico" (jogo mimicry cooperativo):

Objetivos: memorização da letra; repetir o repertório já assimilado.

Material necessário: lápis e papel.

\footnotetext{
${ }^{2}$ A partitura se encontra no link: http://repositorio.unicamp.br/bitstream/REPOSIP/284386/1/Oliveira_CleodicelesBrancoNogueirade_M.p df. Acesso em 15/05/2020. (OLIVEIRA, 2012, p. 63).
} 
Tempo estimado: 10 minutos.

Procedimentos: a/o regente explica o poema, buscando esclarecer toda a sua narrativa. Em seguida, organize pequenos grupos e solicite que as crianças desenhem ou escrevam a história. Por fim, elas organizarão uma pequena dramatização dos principais eventos para socializar suas produções.

Neste exemplo, o tempo e o espaço real do jogo são delimitados objetivamente (dez minutos e o local que cada grupo irá se organizar), e subjetivamente inspirados pelo poema (cenário do poema: barco no rio recontando a narrativa do poema). As regras existem, pois, é esperado que cada grupo se organize coletivamente respeitando seus colegas e ao final todas as crianças precisam apresentar suas produções sem a utilização da letra da canção. De forma criativa e colaborativa, cada grupo estudará a letra da canção, além de desenvolver outras possibilidades de significação do poema.

$\mathrm{Na}$ elaboração de jogos variados, a/o regente precisa conhecer um repertório de atividades que as crianças reconheçam como jogos para poder adaptá-los aos objetivos de ensino. Para auxiliar no processo de reconhecimento dos diferentes universos dos jogos, o autor Caillois (1990) organiza características comuns de atividades sociais que podem ser consideradas jogos, criando quatro categorias: Agôn, Alea, Mimicry, Ilinx. Observa-se que alguns jogos podem transitar entre diferentes categorias de acordo com a sua complexidade.

O primeiro, Agôn, representa os jogos competitivos e para a vitória exige determinado treinamento. A criança campeã é aquela que dentro de uma igualdade compartilhada das regras, supera os adversários se destacando pelas suas habilidades. Esta é uma característica comum, na prática de esportes de alto rendimento. No caso da música, encontra-se este perfil nos festivais competitivos musicais (concurso de piano) ou em grupo (festivais competitivos corais). Especificamente para o coral infantil, fazse necessário ter cuidado para não criar um ambiente com muita rivalidade, dificultando as relações sociais positivas.

Alea é a categoria que define os jogos de sorte e azar. Observa-se que eles ainda apresentam competição, mas não depende das habilidades das/os jogadoras/es para definir os resultados, sendo assim, não necessita de virtuosismo. No caso de a regente 
realizar um sorteio selecionando uma criança para uma ação específica, como um solo, está propondo um jogo desta categoria.

O jogo da categoria Mimicry possui a aceitação ilusória e temporária do deslocamento de uma realidade para uma situação imaginária e este jogo acontece através da dramatização e imitação. Não existe necessariamente uma vitória, a ideia é estimular habilidades cênicas e sociais. Como última categoria, Ilinx é o jogo associado com uma instabilidade sensorial instantânea, dentre outras formas, pelos giros corporais. $\mathrm{Na}$ perspectiva do jogo como ferramenta pedagógica, ele pode ser utilizado para estimular o equilíbrio corporal, bastante relevante para o canto em movimento.

Brito (2003) propõe outra subdivisão dentre os jogos, denominando-os como cooperativos ou competitivos. O primeiro deles (cooperativo) são os desafios em grupo onde é fundamental a participação de todas as pessoas para alcançar o objetivo do jogo. Como benefício de sua prática, compreende-se que "jogando cooperativamente temos a chance de considerar o outro como um parceiro, um solidário, em vez de tê-lo como adversário, operando para interesses mútuos e priorizando a integridade de todos" (BRITO, 2003, p. 54). No coral, o conceito de cooperação é base para as relações sociais do grupo, além de auxiliar na consciência sonora, já que todas as crianças devem cantar com determinada técnica para que o coro tenha uma sonoridade uniforme. Já o competitivo é conceituado com as mesmas características já apresentadas nos jogos da categoria Alea (CALLOIS, 1990). Após a seleção do objetivo de ensino e da criação do universo do jogo, a próxima etapa é a seleção de qual momento o jogo será inserido na rotina do ensaio.

\section{Quando usar o jogo}

Planejar o ensaio significa organizar uma série de ações que serão executadas em períodos pré-determinados. Como sugestão de organização de ensaios corais, a autora e regente Shimiti (1997) propõe uma rotina pontuada da seguinte forma:

- Exercícios corporais objetivando prontidão e postura - de 10 a 15 minutos

- Aquecimento vocal - de 10 a 15 minutos

- Leitura ou montagem de uma música nova - até 10 minutos 
- Recordação de uma ou mais músicas do repertório - até 10 minutos

- Atividade de apoio (procedimentos de musicalização, jogo de atenção ou dinâmica de grupo) de 5 a 10 minutos

- Montagem (ou recordação) de mais duas músicas do repertório que estejam de preferência em diferentes estágios de aprendizagem - até 10 minutos

- Relaxamento ou dinâmica de integração, avisos e encerramento - até 5 minutos (SHIMITI, 1997, p. 125).

Esta citação apresenta três momentos em que estariam enquadrados os jogos: exercícios corporais, atividade de apoio e dinâmica de integração. Este artigo propõe que para além dos momentos citados pela autora Shimiti (1997), os jogos podem acontecer em todas as atividades de acordo com as necessidades das crianças, inclusive nos momentos de leitura musical ou montagem do repertório.

Observa-se que não é fundamental que todas as atividades tenham este perfil, fato que não descarta a relevância do seu uso. A ideia é promover o máximo possível de atividades onde a criança se identifique e tenha prazer com a prática coral e, ao mesmo tempo, aprenda o repertório musical e os demais aspectos da performance.

Entre as dinâmicas básicas da rotina (alongamento, vocalize e passagem do repertório) é possível incorporar os jogos de estimulação ágil que possuam curta duração. O jogo "Estátua" é um exemplo de dinâmica rápida que estimula ludicamente as crianças ficarem atentas às sinalizações da regência. Este jogo pode estar associado a um estímulo sonoro ou algum trecho musical do repertório, isto é, ao invés de escolher aleatoriamente um sinal para as crianças "congelarem", a/o regente seleciona uma sequência sonora que considere importante para ser desenvolvido na percepção das crianças.

O jogo "Vou andar devagarinho" é uma possibilidade de associar o canto com o jogo de estátuas e com as possíveis mudanças de tonalidades também auxilia na ampliação da extensão vocal das crianças. 
4. Jogo "Vou andar devagarinho":

Objetivos: assimilação dos intervalos de segunda maior, terça menor, quarta justa e oitava justa; compreensão da variação de andamento; afinação vocal; expressão corporal.

Tempo estimado: variado.

Procedimentos: após a memorização da canção, a/o regente ou outra criança sugere temáticas variadas para a formação da estátua que é executada no fim da canção, após cantar “congelar”.

\section{VOU ANDAR DEVAGARINHO}
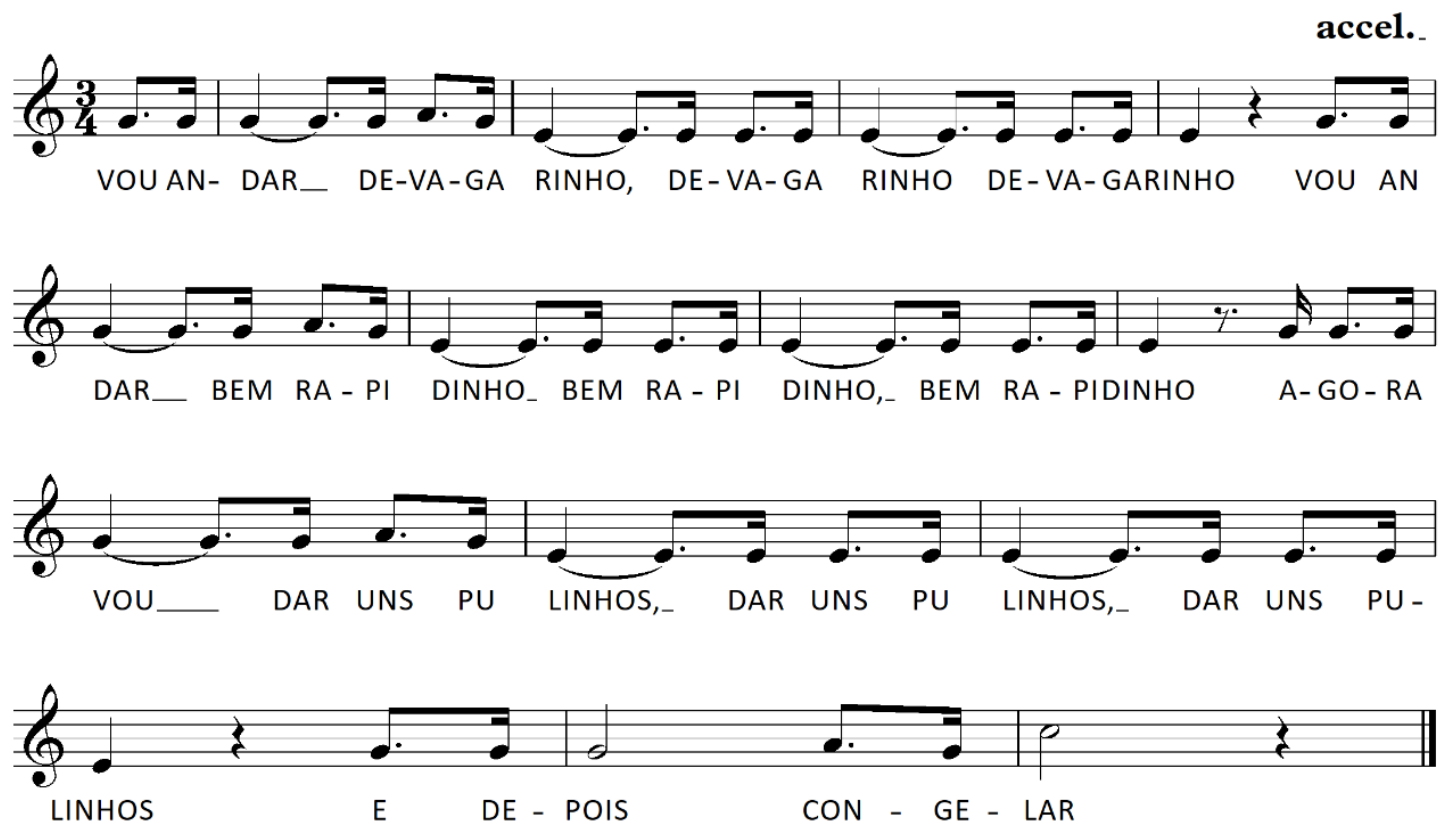

Fonte: KASHIMA, 2014. 
No alongamento ou no aquecimento vocal, os jogos podem derivar dos exercícios já reconhecidos pelo coro alterando a forma de como propô-los, isto é, acrescentam-se os elementos correspondentes ao universo do jogo. Ao invés de utilizar exclusivamente os recursos comuns de imitação para os alongamentos, o mesmo jogo da "Estátua" possibilita que a criança se conscientize corporalmente com mais autonomia e criatividade. Na recordação e repetição do repertório musical, o jogo "Detetive" (algumas crianças são sorteadas sigilosamente para cantar errado um pequeno trecho e as demais precisam descobrir quais são aquelas que estão errando), estimula que as crianças repitam diversas vezes a canção e simultaneamente exercitem a sua percepção de forma mais entretida.

Para ensinar uma canção nova com o uso da partitura, na situação em que o coro não tenha o domínio do solfejo, a/o regente normalmente canta a melodia e as crianças repetem seguindo as suas instruções. No caso da criação de um jogo que projete o aprendizado desta melodia, associado ao ensino da leitura musical, o universo do tradicional Caça-palavras é uma alternativa interessante. Estimuladas em resolver o Caça-palavras, as crianças ficariam atentas a partitura tentando encontrar determinadas figuras musicais, enquanto cantariam a canção, repetidas vezes. Ao invés da repetição mecanizada, esta mudança de proposta teria o potencial de atribuir mais sentido nas ações.

A duração temporal real do jogo corresponde com a sua estrutura e o que for mais conveniente para todo o conjunto de dinâmicas do ensaio, respeitando as necessidades das crianças e o planejamento. Ainda que organizando um período específico para a sua prática, observa-se que quando as crianças demonstrarem desinteresse pela atividade, como já dito anteriormente, deixam de estar jogando tornando a sua continuação quase que despropositada. Fortin (2011) ressalta que a energia e o interesse são necessários para estar jogando com eficácia, assim, quando for avaliada a diminuição da curva de participação motivada, cabe uma interrupção e a troca de proposta. Durante o ensaio é interessante que as crianças tenham uma memória positiva das atividades, dessa forma, terminar o jogo antes do seu desinteresse evita o seu desgaste.

Em síntese, cada regente pode criar jogos de acordo com os seus objetivos de ensino e os interesses das crianças para todos os momentos do ensaio. Espera-se o 
aproveitamento de dinâmicas recreativas para incorporar os saberes projetados das performances. Vale lembrar que somente jogando com as crianças são criadas as possibilidades para avaliar se elas se interessam ou são arrebatas pelo jogo para assim, avaliá-lo como efetivo.

\section{Considerações finais}

O jogo está presente na vida das crianças cotidianamente, sendo praticado em diversos momentos e, por meio dele, são desenvolvidas variadas competências para o seu desenvolvimento. Na infância, encontram-se os jogos nos espaços educacionais por meio de propostas dirigidas com objetivos pedagógicos e nos momentos de mais autonomia e/ou liberdade, na qual as crianças brincam em grupo ou individualmente como parte da cultura em que estão inseridas.

No âmbito coral, organizar os ensaios, responsabilizando-se por uma prática que favoreça o processo de formação das crianças é papel da/o regente. Durante estes encontros são proporcionados os aprendizados para a performance sendo possível avaliar o desenvolvimento do coral e a qualidade das relações sociais das/os participantes. Sabe-se também que o uso da repetição é importante para a aquisição de habilidades específicas que promovam o aperfeiçoamento performático do coral. Desta forma, por meio do jogo é possível que a repetição ganhe outro significado, tornando-a menos maçante e potencialmente mais prazerosa para as/os cantoras/es.

Este artigo propõe etapas para que a/o regente elabore jogos para o ensino da performance. Sendo a primeira delas, a compreensão da função do jogo na educação. $O$ próximo passo pressupõe que o repertório musical já tenha sido escolhido e sugere a projeção da performance do coral para a decodificação dos objetos de estudos que serão ensinados. Obtendo estes dados, cria-se o universo do jogo buscando respeitar as suas características e os interesses das crianças. No ensaio ele pode ocorrer em qualquer momento e quando bem organizado, auxilia no aprendizado de diversas habilidades necessárias para a performance.

O aporte teórico discutido entende o jogo como uma atividade com predominância da subjetividade e a sua ação acontece dentro de uma limitação 
temporal, espacial e precedida de regras. A definição de estar jogando surge pelos jogadores e jogadoras permeadas pela sua cultura, podendo desta forma variar. O principal olhar deve estar sobre como a criança se relaciona com o jogo, pois caso ela não tena interesse, perca a sua motivação ou não esteja assimilando o que era pretendido de ser ensinado, são importantes mudanças e flexibilidade no jogo para a sua efetividade.

A formação em educação musical auxilia a/o regente compreender a necessidade de construir um ensaio em que sejam apresentadas propostas dinâmicas, atento à realidade na qual as crianças estão inseridas e à forma como aprendem, auxiliando na criação dos jogos. Além dos conhecimentos pedagógicos, é fundamental o domínio dos conteúdos musicais, para que a organização dos ensaios beneficie também o aprendizado musical do coro, construindo, assim, um repertório artístico gradativamente mais complexo.

Acrescenta-se que a amplitude do espaço dos ensaios com cadeiras removíveis favorece os jogos de exploração espacial, caso não obtenha esta estrutura, diversas atividades precisam de adaptação reduzindo o potencial do uso de determinados jogos. Em relação ao pianista correpetidor, caso o coro não o tenha, a/o regente precisa ocupar dois papéis nos ensaios. Este contexto exige que a/o regente busque jogos com acompanhamento musical em gravações ou organizar que as próprias crianças cantem ou toquem.

Respeitando as etapas descritas nesta pesquisa, espera-se que a/o regente se sensibilize pela prática do jogo, e obtenha os instrumentos para criá-lo e oportunizá-lo às crianças. Destaca-se principalmente a inclusão do jogo nos momentos onde ele comumente não se encontra, como nas repetições mecanizadas ou nos processos de memorização do repertório. Por fim, diversos conteúdos podem ser ensinados pelo jogo, ou até mesmo a hipótese de que todo ensaio possa ser lúdico, entretido, musical e que a criança se divirta cantando e brincando. 


\section{Referências}

ALMEIDA, Theodora M. M. de. Quem canta seus males espanta 2. São Paulo: Caramelo, 2000.

BRITO, Teca A. Música na educação infantil. São Paulo: Ed. Fundação Petrópolis, 2003.

BROUGERE, Gilles. A criança e a cultura lúdica. Rev. Fac. Educ. São Paulo, v. 24, n. 2, p. 103-116, 1998.

CAILLOIS, Roger. O jogo e os homens: a máscara e a vertigem. Tradução de José G. Pallha. Lisboa: Ed. Livros Cotovia, 1990.

CLARKE, Eric. Processos cognitivos da performance. Revista Música, Psicologia e Educação, Porto, $\mathrm{n}^{\circ}$ 1, 61-76, 1999. Disponível em: http://hdl.handle.net/10400.22/3121. Acesso em: $1 \mathrm{abr}$. 2020.

COLL, César. Introdução. In: COLL, Cesar; POZO, Juan; SARABIA, Barnabé; VALLS, Enric. Os conteúdos na reforma: ensino e aprendizagem de conceitos, procedimentos e atitudes. Porto Alegre: Artes Médicas, 2000.

CÓRIA-SABINI, Maria A.; LUCENA, Regina F. Jogos e Brincadeiras na Educação Infantil. $2^{\mathrm{a}}$ Edição. Campina: Papirus, 2004.

FIGUEIREDO, Sérgio L. F. de. O ensaio coral como momento de aprendizagem: a prática coral numa perspectiva de educação musical. MARTINS, Raimundo (orientador). Dissertação (Mestrado em Música) /Instituto de Artes, UFRGS, Porto Alegre, 1990.

FONTERRADA, Marisa T. de O. De tramas e fios: um ensaio sobre música e educação. São Paulo: Editora UNESP, 2003.

FORTIN, Christine. 100 jogos cooperativos. São Paulo: Ground, 2011.

FREIRE, João B. O jogo: entre o riso e o choro. Campinas: Autores Associados, 2002.

HUIZINGA, Joan. Homo ludens. Tradução de João P. Monteiro e Newton Cunha. São Paulo: Perspectiva, 1995.

KASHIMA, Rafael K. A função e o desenvolvimento do jogo didático nos ensaios de coros infantis, MENDES, Adriana (orientadora). Dissertação (Mestrado em Música) /Instituto de Artes, UNICAMP, Campinas, 2014.

KISHIMOTO, Tizuco M. Jogo, brinquedo, brincadeira e a educação. São Paulo: Cortez, 2006.

KOUDELA, Ingrid D. Jogos teatrais. São Paulo: Ed. Perspectiva, 2007.

NEGRINE, Airton. Aprendizagem e desenvolvimento infantil. Porto Alegre: Propil, 1994.

OLIVEIRA, Cleodiceles B. N. de. A prática do canto coral infantil como processo de musicalização. 72 páginas. Orientador: FIORINI, Carlos F. Dissertação (Mestrado em Música) /Instituto de Artes, UNICAMP, Campinas, 2012. 
SHIMITI, Lucy M. O ensaio. In: SESC SÃO PAULO (Org.) Canto, canção, cantoria: como montar um coral infantil. São Paulo: SESC, 1997, p. 120-132.

SPOLIN, Viola. Jogos teatrais, o fichário de Viola Spolin. São Paulo: Perspectiva, 2006.

STAALDUINEN, Jean-Paul Van; FREITAS Sara de. A Game-Based Learning Framework: Linking Game Design and Learning Outcomes. In: KHINE, Myint S. Learning to play. Exploring the future of education with video games. Nova York: Peter Lang, 2011. Cap. 3.

STOROLLI, Wânia M. A. O corpo em ação: a experiência incorporada na prática musical. Revista da ABEM, v. 19, n. 25, p. 131-140, 2014.

VIGOTSKI, Lev S. A formação social da mente: o desenvolvimento dos processos psicológicos superiores. São Paulo: Martins Fontes, 2000. 